\title{
A rapid and efficient in vitro regeneration system for lettuce (Lactuca sativa L.)
}

\author{
Isabel Armas* (10, Natalia Pogrebnyak and Ilya Raskin
}

\begin{abstract}
Background: Successful biotechnological improvement of crop plants requires a reliable and efficient in vitro regeneration system. Lettuce (Lactuca sativa L.), one the most important vegetable crops worldwide, is strongly genotypedependent in terms of regeneration capacity, limiting the potential for biotechnological improvement of cultivars which show recalcitrance under currently available protocols. The effect of different nutrient sources, plant hormone combinations and activated charcoal supplementation on shoot induction efficiency was evaluated on the cultivar 'RSL NFR', which had previously shown poor regeneration efficiency.

Results: Multiple shoot organogenesis from cotyledon explants was recorded at the highest frequency and speed on Murashige and Skoog regeneration medium supplemented with $200 \mathrm{mg} / \mathrm{l}$ of activated charcoal, 3\% sucrose, $10 \mathrm{mg} / \mathrm{l}$ benzylaminopurine and $0.5 \mathrm{mg} / \mathrm{l}$ naphthaleneacetic acid, which induced shoots through direct regeneration in $90.8 \pm 7.9 \%$ of explants. High shoot induction efficiency was also observed, albeit not quantified, when using this medium on some other cultivars.

Conclusions: This activated charcoal-containing regeneration medium might offer a rapid and efficient option for direct shoot induction in some lettuce genotypes that do not respond well to common lettuce regeneration protocols. This is also the first report of the effect of activated charcoal in lettuce tissue culture.
\end{abstract}

Keywords: Lactuca sativa, Tissue culture, Shoot induction, Regeneration efficiency, Activated charcoal

\section{Background}

Lettuce (Lactuca sativa L.) is a leafy herbaceous selfpollinated annual plant of the family Asteraceae, grown worldwide for consumption, most commonly raw, as a salad green. The Food and Agriculture Organization of the United Nations estimated worldwide production of lettuce (combined with chicory) to be almost 25 million metric tons in 2014, with a gross production value close to US\$12,000 million as of 2012 [1]. Lettuce is therefore a good candidate for agronomic trait improvement, including the delivery of nutrients and bioactive compounds beneficial to human health. Following this line of reasoning, lettuce varieties with traits such as herbicide

\footnotetext{
${ }^{*}$ Correspondence: isabel.argu@rutgers.edu

Department of Plant Biology, School of Environmental and Biological Sciences, Rutgers, The State University of New Jersey, New Brunswick, NJ 08901, USA
}

resistance [2], virus resistance [3], environmental stress resistance [4, 5], yield enhancement [6], accumulation of pharmaceutical proteins $[7,8]$, increased leaf calcium content [9], and increased total polyphenol content [10, 11], have been developed.

Successful plant genetic engineering, as well as of some non-transgenic approaches such as screening plantlets for a desired phenotype using an in vitro platform, ultimately rest on the ability to regenerate whole plants reliably and efficiently through tissue culture. A regeneration system which induces rapid multiple shoot production, without a slow intermediate callus stage, is preferred for most applications. The progress and efficiency of regeneration can be influenced by three major factors: selection of a cultivar with adequate regeneration efficiency, optimization of explant source, and adaptation of the medium for the given genotype [12-14]. Medium 
optimization involves selecting a salt and vitamin mix, a carbon source, and the most adequate hormone combination. It may also be possible to further optimize media by adding supplements which induce beneficial effects on regeneration even if they are not strictly necessary, due to their additional nutrient content or their physicochemical properties, such as the addition of coconut water, potato extract, banana homogenate or algal compounds to orchid tissue culture media [15].

In the case of lettuce the regeneration response has been reported to be highly variable across experiments and dependent on genotype $[12,13,16]$, with many cultivars showing strong recalcitrance. Shoot organogenesis can be induced by culturing 3-7 day old cotyledon explants on a variety of solid media, and different hormone combinations have been evaluated over the years for the best regeneration results [12-14, 17-23]. One of the most common approaches uses a medium defined by Hunter and Burritt [21] which is reported to produce up to $72 \%$ direct shoot regeneration [14], containing $0.09 \mathrm{mg} / \mathrm{l}(0.44 \mu \mathrm{M})$ of the cytokinin benzylaminopurine $(\mathrm{BA})$ and $0.1 \mathrm{mg} / \mathrm{l}(0.54 \mu \mathrm{M})$ of the auxin naphthaleneacetic acid (NAA), or minor variations $[22,23]$. Nevertheless none of the available regeneration protocols offer consistent results across all cultivars, making optimization on a case-by-case basis critical for the improvement of recalcitrant genotypes.

Improvement of cultivar 'RSL NFR' through phenotype selection in vitro was delayed by the low shoot induction rates obtained using an in-house medium containing Murashige and Skoog (MS) salt mixture with Gamborg vitamins, $3 \%$ sucrose, $2 \mathrm{mg} / \mathrm{l} \mathrm{BA}$ and $0.1 \mathrm{mg} / \mathrm{l}$ NAA. Regeneration took place through an intermediate callus stage, with shoots developing 4-6 weeks after cotyledon excision and no more than $10 \%$ of explants producing shoots (unpublished data). In the present study we attempted to optimize medium composition to induce fast multiple shoot induction, and also healthy shoots, in 'RSL NFR'. The relatively low efficiency medium originally used was tested side by side with each variation as a control. All variations were tested on 'RSL NFR' and on 'Winter Density', a cultivar where high callus production and very low shoot induction efficiency had been observed. A strong and consistent improvement in multiple shoot induction frequency and speed was observed on regeneration medium supplemented with $200 \mathrm{mg} / \mathrm{l}$ activated charcoal (AC), observable as early as 10 days after explant excision.

\section{Methods}

\section{Chemicals and reagents}

Murashige and Skoog modified basal salt mixture with Gamborg vitamins, Schenk and Hildebrandt modified basal salt mixture with vitamins, micropropagation grade agar, benzylaminopurine solution, kinetin solution, thidiazuron solution, zeatin solution, naphthaleneacetic acid solution and indolebutyric acid solution were purchased from PhytoTechnology Laboratories (Overland Park, KS, USA). Activated charcoal, glucose and sucrose were purchased from Sigma (St. Louis, MO, USA).

\section{Tissue culture conditions}

Seeds of loose leaf 'RSL NFR' lettuce provided by Shamrock Seed Company (Salinas, CA, USA) and of romaine 'Winter Density' lettuce (Johnny's Selected Seeds, Winslow, ME, USA) were surface sterilized by immersion in $70 \%$ ethanol for $1 \mathrm{~min}$, followed by a $1.2 \%$ sodium hypochlorite solution for $12 \mathrm{~min}$ and rinsed three times with sterilized distilled water. Surface sterilized seeds were placed into deep Petri dishes (VWR, Radnor, PA, USA) containing $40 \mathrm{ml}$ of germination medium solidified with $7 \mathrm{~g} / \mathrm{l}$ agar (Table 1 ). Three days after germination the cotyledons were aseptically excised and placed into deep Petri dishes containing $40 \mathrm{ml}$ of different types of shoot induction media solidified with $7 \mathrm{~g} / \mathrm{l}$ agar (Tables 2, 3). Petri dishes were kept inside a GC-96 CW walk-in environmentally controlled growth chamber (EGC, Chagrin Falls, OH, USA) at $22{ }^{\circ} \mathrm{C}$, under a photosynthetically active radiation (PAR) light intensity of $10.6 \pm 1.7 \mathrm{~mol} /$ $\mathrm{m}^{2}$ day provided by full spectrum 32W Philips F32T8/ DX fluorescent lamps (Philips, Andover, MA, USA) and a 16/8 h (light/dark) photoperiod. Petri dishes were checked weekly for any changes.

\section{Experimental design and analysis of results}

Each treatment group comprised 15 cotyledon explants contained in a single Petri dish and all treatments were replicated a minimum of three times, totaling at least $\mathrm{N}=45$ explants per treatment group. The earliest signs of shoot induction were recorded, and the effects of each medium on shoot induction rate and shoot quality were evaluated at weeks 6 and 8. The percentage of explants with at least one shoot was recorded for each treatment

\section{Table 1 Tissue culture media originally used on 'RSL NFR'}

\begin{tabular}{lllll}
\hline Medium & $\begin{array}{l}\text { Basal salt } \\
\text { mix }\end{array}$ & Sugar & $\begin{array}{l}\text { Cytokinins } \\
\text { (mg/l) }\end{array}$ & $\begin{array}{l}\text { Auxins } \\
\text { (mg/l) }\end{array}$ \\
\hline Germination & MS $1 / 2 \times$ & Sucrose 1\% & - & - \\
Shoot induction & MS $1 \times$ & Sucrose 3\% & BA 2 & NAA 0.1 \\
Root induction & MS $1 \times$ & Sucrose 3\% & - & IBA 1
\end{tabular}

All media pH was adjusted to 5.7 , solidified with $7 \mathrm{~g} / \mathrm{l}$ agar and autoclaved at $121^{\circ} \mathrm{C}$ and $103 \mathrm{kPa}$ for $20 \mathrm{~min}$. Shoot induction medium was used as a control for all optimization experiments

MS Murashige and Skoog modified basal salts with Gamborg vitamins, $B A$ 6-benzylaminopurine, NAA naphthaleneacetic acid, IBA indole-3-butyric acid 
Table 2 Nutritional and hormonal variations of regeneration media

\begin{tabular}{|c|c|c|c|c|}
\hline Medium & $\begin{array}{l}\text { Basal salt } \\
\text { mix }\end{array}$ & Sugar & $\begin{array}{l}\text { Cytokinins } \\
\text { (mg/l) }\end{array}$ & Auxins (mg/l) \\
\hline Control & MS 1x & Sucrose 3\% & BA 2 & NAA 0.1 \\
\hline M1 & $\mathrm{SH} 1 \times$ & Sucrose 3\% & BA 2 & NAA 0.1 \\
\hline M2 & MS $1 \times$ & Glucose 1.5\% & BA 2 & NAA 0.1 \\
\hline M3 & MS $1 \times$ & Sucrose 3\% & BA 0.09 & NAA 0.1 \\
\hline M4 & MS $1 \times$ & Sucrose 3\% & KIN 2 & NAA 0.1 \\
\hline M5 & MS 1x & Sucrose 3\% & TDZ 2 & NAA 0.1 \\
\hline M6 & MS $1 \times$ & Sucrose 3\% & ZEA 2 & NAA 0.1 \\
\hline M7 & MS $1 \times$ & Sucrose 3\% & BA 1 & NAA 0.05 \\
\hline M8 & MS $1 \times$ & Sucrose 3\% & BA 3 & NAA 0.15 \\
\hline M9 & MS $1 \times$ & Sucrose 3\% & BA 4 & NAA 0.2 \\
\hline M10 & MS $1 \times$ & Sucrose $3 \%$ & BA 5 & NAA 0.25 \\
\hline M11 & MS $1 \times$ & Sucrose 3\% & BA 6 & NAA 0.3 \\
\hline M12 & MS $1 \times$ & Sucrose 3\% & BA 7 & NAA 0.35 \\
\hline M13 & MS $1 \times$ & Sucrose 3\% & BA 8 & NAA 0.4 \\
\hline M14 & MS $1 \times$ & Sucrose 3\% & BA 9 & NAA 0.45 \\
\hline
\end{tabular}

All media $\mathrm{pH}$ was adjusted to 5.7 , solidified with $7 \mathrm{~g} / \mathrm{l}$ agar and autoclaved at $121^{\circ} \mathrm{C}$ and $103 \mathrm{kPa}$ for $20 \mathrm{~min}$

MS Murashige and Skoog modified basal salts with Gamborg vitamins, $S H$ Schenk and Hildebrandt modified basal salts with vitamins, $B A$ benzylaminopurine, KIN kinetin, TDZ thidiazuron, ZEA zeatin, NAA naphthaleneacetic acid

Table 3 Activated charcoal supplementation of regeneration media

\begin{tabular}{|c|c|c|c|c|c|}
\hline Medium & $\begin{array}{l}\text { Basal salt } \\
\text { mix }\end{array}$ & Sugar & $\begin{array}{l}\text { Cytokinins } \\
\text { (mg/l) }\end{array}$ & $\begin{array}{l}\text { Auxins } \\
(\mathrm{mg} / \mathrm{l})\end{array}$ & $\begin{array}{l}\text { AC } \\
(\mathrm{mg} / \mathrm{l})\end{array}$ \\
\hline Control & MS $1 \times$ & Sucrose 3\% & BA 2 & NAA 0.1 & - \\
\hline M15 & MS $1 \times$ & Sucrose 3\% & BA 2.5 & NAA 0.125 & 20 \\
\hline M16 & MS $1 \times$ & Sucrose 3\% & BA 5 & NAA 0.25 & 20 \\
\hline M17 & MS $1 \times$ & Sucrose 3\% & BA 2.5 & NAA 0.125 & 200 \\
\hline M18 & MS $1 \times$ & Sucrose 3\% & BA 5 & NAA 0.25 & 200 \\
\hline M19 & MS $1 \times$ & Sucrose 3\% & BA 10 & NAA 0.5 & 200 \\
\hline M20 & MS $1 \times$ & Sucrose 3\% & BA 5 & NAA 0.25 & 2000 \\
\hline M21 & MS $1 \times$ & Sucrose 3\% & BA 10 & NAA 0.5 & 2000 \\
\hline
\end{tabular}

All media $\mathrm{pH}$ was adjusted to 5.7 , solidified with $7 \mathrm{~g} / \mathrm{l}$ agar and autoclaved at $121^{\circ} \mathrm{C}$ and $103 \mathrm{kPa}$ for $20 \mathrm{~min}$

$A C$ activated charcoal, MS Murashige and Skoog modified basal salts with Gamborg vitamins, BA benzylaminopurine, NAA naphthaleneacetic acid

group, and the size, growth speed, morphology and health conditions of shoots were evaluated visually. The means and standard deviations (SD) were calculated from pooled data and all results are expressed as mean \pm SD. The statistical significance of the differential effects of treatments was determined using a general linear model analysis of variance (ANOVA) followed by a Dunnett test. A global significance level was set at $\alpha=0.05$. All statistical procedures were performed using GraphPad Prism 6 (GraphPad Software Inc., La Jolla, CA, USA).

\section{Results}

Nutritional and hormonal variations of the shoot induction medium

Modification of the salt mix and sugar components of the original medium yielded no significant changes when compared to the control medium (Fig. 1, M1-M2). Substituting the Murashige and Skoog (MS) basal salt mixture for Schenk and Hildebrandt (SH) basal salt mixture (Table 2, M1), sometimes used in lettuce shoot induction [12, 13, 20], produced no changes. A 1992 study by Teng et al. concluded that a regeneration medium containing glucose induces more shoot induction and less callus growth in lettuce than a regeneration medium containing sucrose [20]. However our results show no differences (Table 2, M2) aside from the development of hyperhydric calli (Fig. 2b), which has been previously correlated with an overall decrease in regeneration efficiency.

On the other hand, changes to the hormonal composition of the original medium affected regeneration efficiency (Fig. 1, M3-M14), especially in cultivar 'RSL NFR', where shoot induction was overall higher and more responsive to medium modifications than in cultivar 'Winter Density'. The medium defined by Hunter and Burritt [21] (Table 2, M3) induced a significant increase in shoot count, size and growth speed, with $60 \pm 21.5 \%$ of 'RSL NFR' explants producing at least one shoot. These shoots developed directly from explant tissue 2 weeks after excision, in marked contrast to the control. However, the morphology observed for these shoots was markedly abnormal with typical symptoms of etiolation: elongated stems with very thin and narrow leaf blades, chlorosis and overall weakness (Fig. 2c).

Substitution of the cytokinin BA for kinetin or thidiazuron (TDZ) (Table 2, M4-M5) induced minor changes which were not statistically significant. Shoots induced by kinetin were comparable in size, growth speed and morphology (Fig. 2d) to those in the control group, whereas shoots induced by TDZ were smaller and weaker (Fig. 2e); regeneration was in all cases slow and mediated through a callus stage. Zeatin (Table 2, M6), however, induced a significant increase in shoot count, size and growth speed, with $82.2 \pm 3.8 \%$ of 'RSL NFR' explants producing at least one shoot. These shoots developed directly from explant tissue 2 weeks after excision, being later followed by a moderate amount of roots and callus. These shoots, however, showed aberrant morphology, with elongated stems and very irregularly shaped leaf blades (Fig. 2f).

A range of hormone concentrations, from $1 \mathrm{mg} / \mathrm{l} \mathrm{BA}$ and $0.05 \mathrm{mg} / \mathrm{l} \mathrm{NAA}$ to $9 \mathrm{mg} / \mathrm{l} \mathrm{BA}$ and $0.45 \mathrm{mg} / \mathrm{l} \mathrm{NAA}$, were also evaluated (Table 2, M7-M14). A significant increase in shoot induction was observed for 'RSL NFR' grown on medium M7. These shoots developed directly 


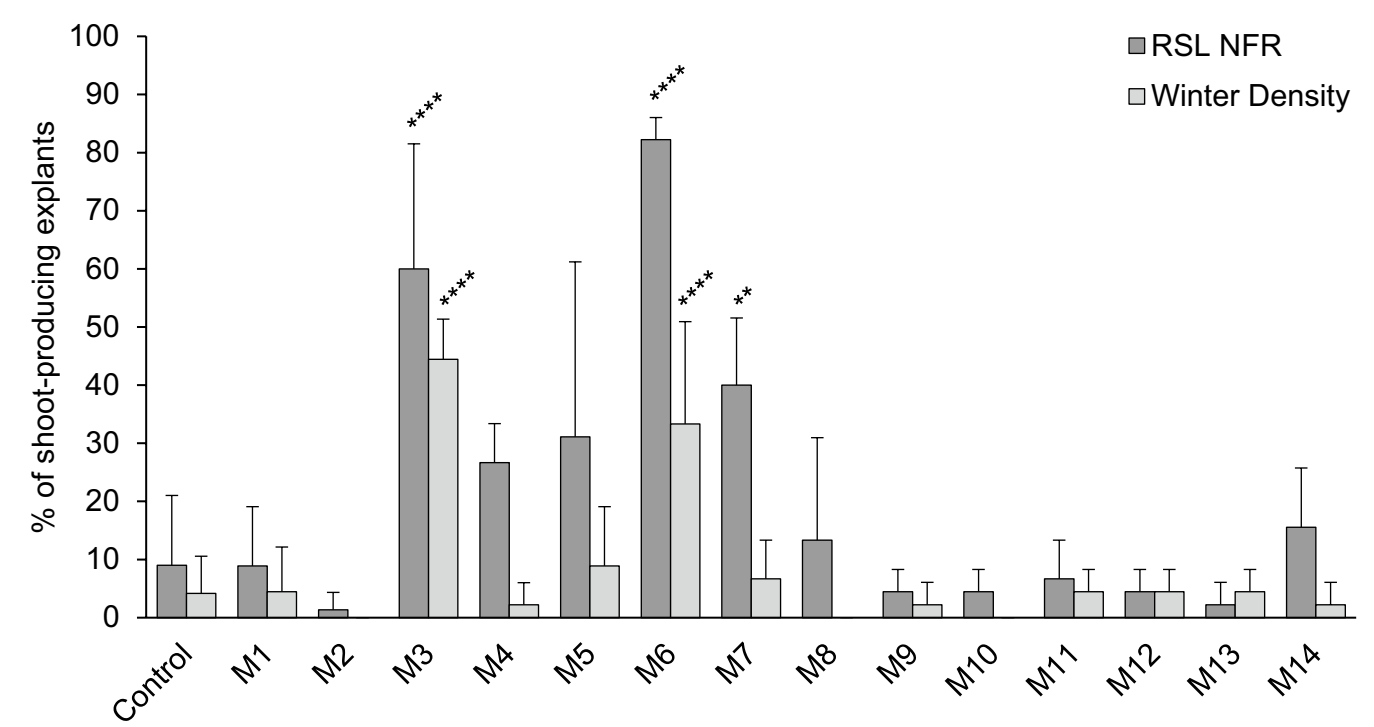

Fig. 1 Shoot induction in cultivars 'RSL NFR' and 'Winter Density' under different nutritional and hormonal conditions but no AC. The number of explants which produced at least one shoot 8 weeks after excision were quantified for all treatment groups and expressed as a percentage of the total explant number. A minimum of $\mathrm{N}=45$ explants were evaluated per treatment group. Data were pooled and are presented as mean \pm SD. Significant differences between the control group and each treatment group were analyzed by a one-way ANOVA followed by a Dunnett test $\left({ }^{* *} p \leq 0.01,{ }^{* * * *} p \leq 0.0001\right)$. Data does not reflect size, growth speed or overall quality of the shoots

from explant tissue 2 weeks after excision, but overall looked weak, growing very slowly and showing symptoms of etiolation (Fig. 2g). Regeneration on media M8M14 was very low, with all shoots developing indirectly from an intermediate callus stage, growing very slowly and often arresting their growth altogether (Fig. $2 \mathrm{~h}$ ).

\section{Supplementation of the shoot induction medium with activated charcoal}

The range of AC concentrations used in plant tissue culture is highly variable, from reports of Brassica microspore embryogenesis being supplemented with $150 \mathrm{~g} / \mathrm{l}$ $\mathrm{AC}$ [24], to $0.002 \mathrm{~g} / \mathrm{l} \mathrm{AC}[25,26]$ being used for root induction in Capsicum sp. and Aesculus sp. Additionally, it has been shown that a large proportion of the hormones present in the regeneration medium are very quickly adsorbed by the AC particles, making it difficult to know the amounts and ratios which are available to the plant tissue [27-31]. Medium supplementation with $\mathrm{AC}$ therefore requires careful optimization of the relative amounts of both $\mathrm{AC}$ and hormones.

AC was incorporated to the medium in a concentration of 20,200 and $2000 \mathrm{mg} / \mathrm{l}$, while increasing the amounts of BA and NAA proportionally to compensate for their adsorption. Significant differences were observed between treatments in cultivar 'RSL NFR' (Fig. 3). The combination of $20 \mathrm{mg} / \mathrm{l} \mathrm{AC}$ with $2.5 \mathrm{mg} / \mathrm{l} \mathrm{BA}$ and $0.125 \mathrm{mg} / \mathrm{l} \mathrm{NAA}$ (Table 3, M15) produced a significant increase in shoot count, size and growth speed when compared to the control medium with no AC (Fig. 4b). However, the same amount of charcoal combined with $5 \mathrm{mg} / \mathrm{l} \mathrm{BA}$ and $0.25 \mathrm{mg} / \mathrm{l} \mathrm{NAA}$ (Table 3, M16) induced no significant changes. Addition of $200 \mathrm{mg} / \mathrm{l} \mathrm{AC}$ produced a strong and significant increase in shoot count, size and development speed on media containing either $5 \mathrm{mg} / \mathrm{l}$ BA and $0.25 \mathrm{mg} / \mathrm{l}$ NAA (Table 3, M18) or $10 \mathrm{mg} / \mathrm{l} \mathrm{BA}$ and $0.5 \mathrm{mg} / \mathrm{l} \mathrm{NAA}$ (Table 3, M19). These shoots initiated development directly from explant tissue around day 10 , and almost all explants produced multiple shoots (Fig. 4d, e). Addition of $2000 \mathrm{mg} / \mathrm{l} \mathrm{AC} \mathrm{(Table} \mathrm{3,} \mathrm{M20-M21),} \mathrm{how-}$ ever, induced no reaction in the tissue regardless of the hormonal dose (Fig. 4f), most likely due to a lack of available hormones due to their complete adsorption by the AC particles present. Media 15, 16, 18, 19, 20 and 21 were evaluated again in a second set of identical experiments which produced very similar results. Overall, rapid and multiple shoot induction was recorded from $64 \pm 37 \%$ of all 'RSL NFR' explants in medium M18 and $86.7 \pm 9.4 \%$ of all 'RSL NFR' explants in medium M19.

We attempted to further adjust the hormonal dose added to media containing $200 \mathrm{mg} / \mathrm{l} \mathrm{AC}$ by comparing media M18 and M19 to a medium containing $2.5 \mathrm{mg} / \mathrm{l}$ BA and $0.125 \mathrm{mg} / 1$ NAA (Table 3, M17). The results confirmed the trend observed in the previous experiments and showed a clear dose-response effect, with increased hormone content leading to increased shoot induction efficiency within the tested range (Fig. 3). Shoots initiated development directly from explant tissue between 

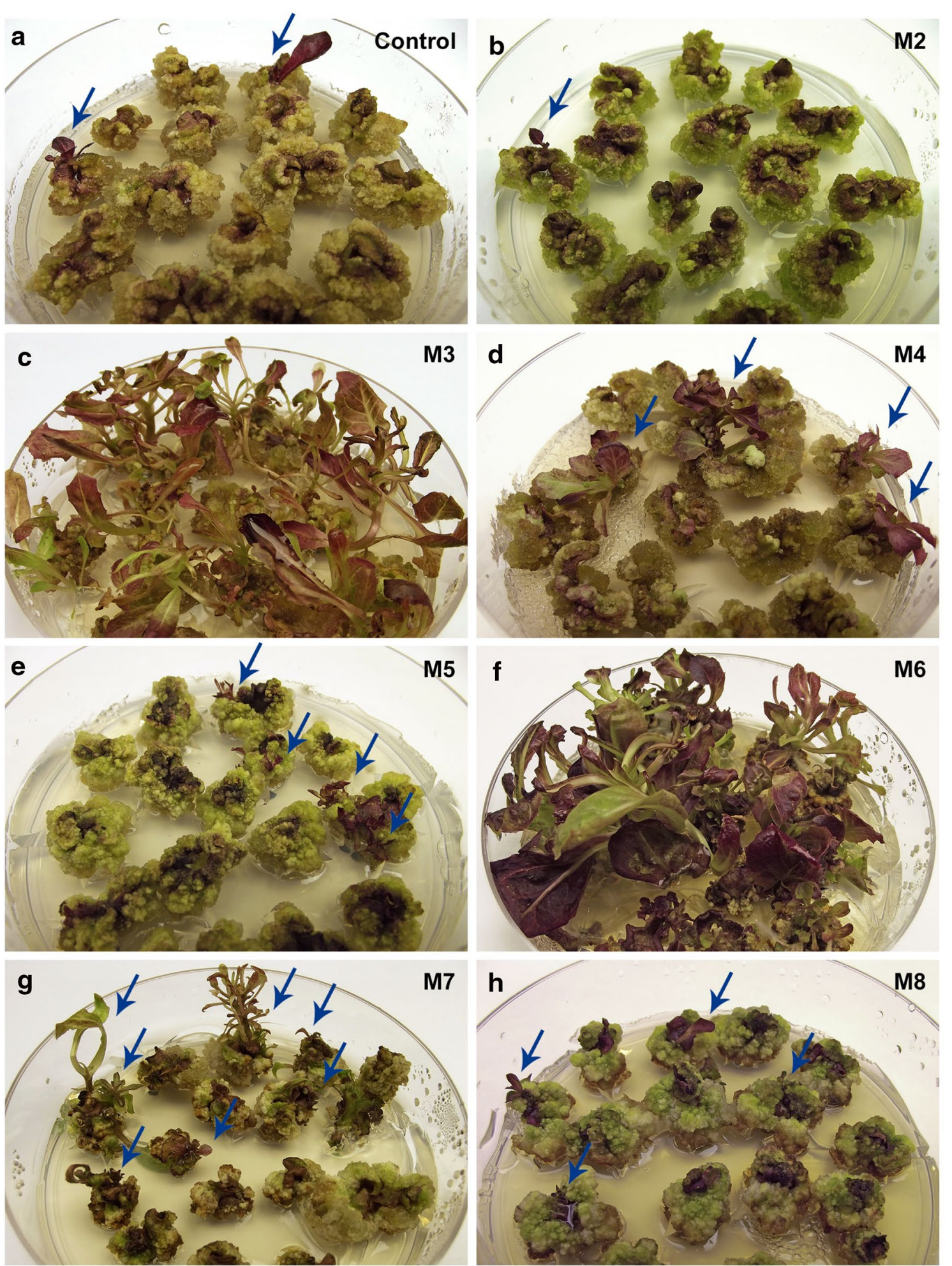

Fig. 2 Visual comparison of shoots induced under different nutritional and hormonal conditions but no AC. No significant differences in shoot count, size and growth speed were observed between the control medium (a) and media M2 (b), M4 (d), M5 (e), or M8-M14 (h). Significant improvements were observed on media M3 (c) and M6 (f), and to a lesser degree also in M7 (g); however in all cases the shoots appeared weak, etiolated, or showed an aberrant morphology when compared to the control. All images are of cultivar 'RSL NFR' at week 7. Shoots which may be hard to discern are marked with arrows 


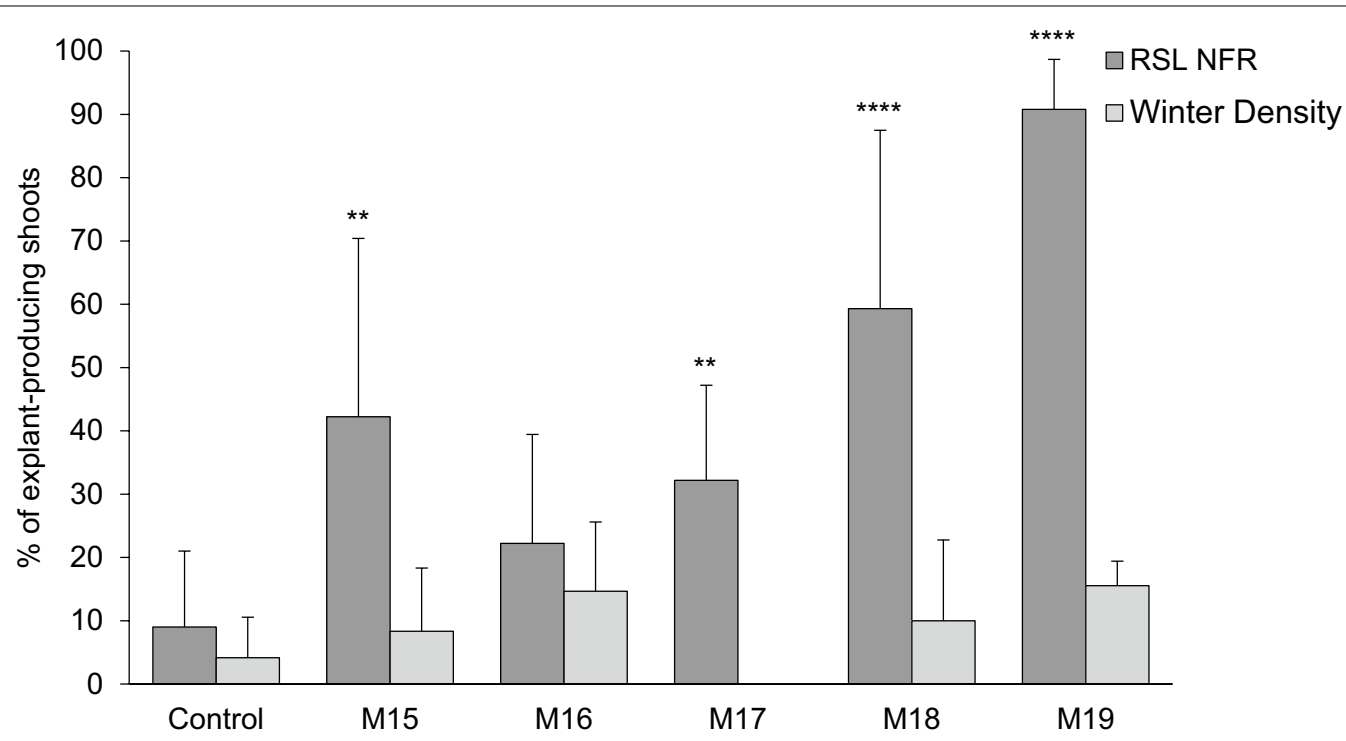

Fig. 3 Shoot induction in cultivars 'RSL NFR' and 'Winter Density' under increasing concentrations of AC. The number of explants which produced at least one shoot 8 weeks after excision were quantified for all treatment groups and expressed as a percentage of the total explant number. A minimum of $\mathrm{N}=45$ explants were evaluated per treatment group, and a minimum of $\mathrm{N}=120$ explants were evaluated for treatment groups $\mathrm{M} 17, \mathrm{M} 18$ and M19. Data were pooled and are presented as mean \pm SD. Significant differences between the control group and each treatment group were analyzed by a one-way ANOVA followed by a Dunnett test $\left({ }^{* *} p \leq 0.01,{ }^{* * * *} p \leq 0.0001\right)$. Data does not reflect size, growth speed or overall quality of the shoots. Media M20 and M21 not shown since no shoots were produced for either cultivar. Media M17 not shown for cultivar 'WD'since it was tested only on cultivar 'RSL NFR'

day 10 and 14 (Fig. 4g), often appeared in bundles of multiple shoots and showed normal morphology, although variability between Petri dishes in terms of shoot size and growth speed was higher than in previous experiments. Medium M17 induced healthy shoot formation from $32.2 \pm 15 \%$ of 'RSL NFR' explants (Fig. 4c), a significant increase from the $9 \pm 12 \%$ recorded under control conditions, yet much lower than the cumulative final values for media M18 and M19, $59.3 \pm 28.2$ and $90.8 \pm 7.9 \%$ respectively. Comparison of results across all Petri dishes and experiment repeats showed the highest result consistency for medium M19 (see shoot induction rates per individual Petri dish in Additional file 1).

Despite AC supplementation not inducing any statistically significant changes in the percentage of explants which produced shoots in cultivar 'Winter Density' (Fig. 3), it must be noted that most regenerated shoots started direct development around week 2, in strong contrast to the control where shoots developed through an intermediate callus stage. High frequency direct regeneration on medium M19 was also observed, even if not quantified, in cultivars 'Paris White,' 'Lettony', 'Simpson Elite' and 'Bambi' (Fig. 4h).

\section{Discussion}

It has been long known that in vitro regeneration of lettuce can take months if using an inadequate combination of explant source and medium composition [20], limiting its potential for biotechnological improvement. Given how regeneration efficiency in lettuce is statistically dependent on genotype $[12,13,16]$ it may not be possible to define a single medium that induces high levels of shoot induction across all existing cultivars. Different studies in lettuce tissue culture have focused on ranking different cultivars according to their callus formation or direct shoot induction capacities [12, 22]. Situations where the cultivar of interest must be chosen according to different criteria, however, make a strong case for the development of alternative regeneration conditions for recalcitrant cultivars.

In 'RSL NFR', medium M19 consistently increased shoot organogenesis from approximately $10 \%$ of explants producing single shoots in the control medium, to multiple shoot induction from at least $70 \%$ of explants in all individual Petri dishes evaluated, and up to an average of $90 \%$. This medium also decreased the time required for initiation of shoot organogenesis from up to 6 weeks in the control medium to under 2 weeks. These shoots developed roots successfully when transferred to root induction medium, the plantlets survived transplantation to potting mix, and the adult plants were able to produce viable seeds. Observation of the effects of medium M19 on other loose leaf and romaine lettuce cultivars showed that the beneficial effect of $\mathrm{AC}$ is still conditioned by the lettuce genotype, with some of the genotypes barely 

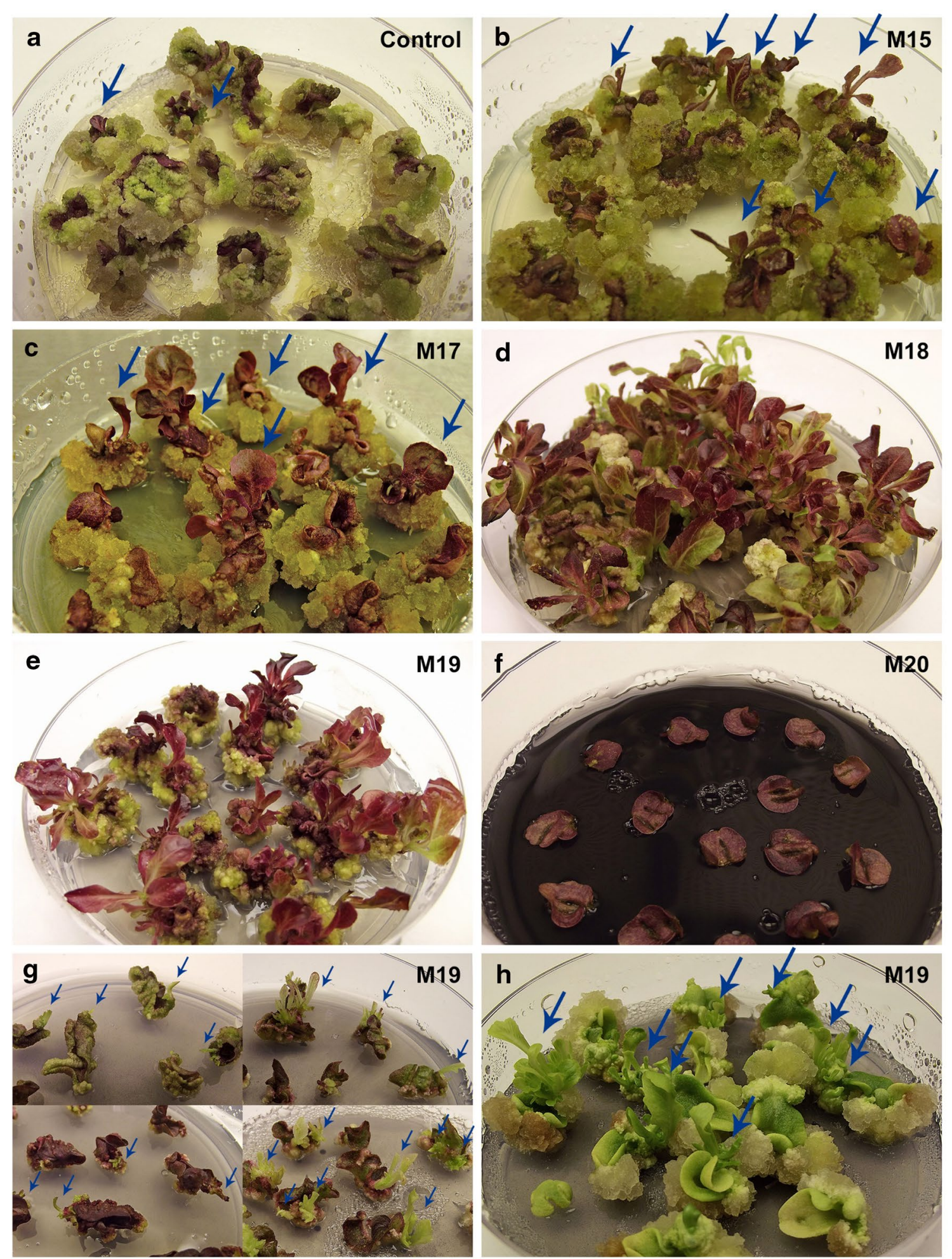

Fig. 4 Visual comparison of shoots induced under increasing concentrations of AC. A significant increase in shoot count, size and growth speed over the control medium (a) was observed on media M15 (b), M17 (c), and especially M18 (d) and M19 (e). Tissue did not react on media M20 and M21 (f). All observed shoots were produced through direct regeneration, initiating development from explant tissue between days 10 and 14 (g), and grew at a moderate speed with normal morphology. All images are of cultivar 'RSL NFR', except for $\mathbf{h}$ which shows cultivar 'Bambi'. All treatments are shown at week 7, except for $\mathbf{g}$ which shows direct initiation of shoot development at week 2. Shoots which may be hard to discern are marked with arrows 
modifying their previous response when under the presence of $\mathrm{AC}$, and with others showing direct and rapid shoot induction, high frequency of shoot organogenesis, or both. Despite the lack of a uniform response, we believe our results highlight the worth of testing M19 or in general any AC-containing media when attempting regeneration of recalcitrant cultivars. It may be of value, for example, to test a range of $\mathrm{AC}$ concentrations on the commonly used Hunter and Burritt medium (M3), or on media containing zeatin (M6).

Given the lack of significant changes observed in media containing increased amounts of total BA and NAA (M8M14) it seems unlikely that the results observed in media M18 and M19 are solely influenced by the high hormone levels. A more likely reason behind the observed improvement would be the physicochemical properties of AC, which is processed to have a large network of very fine pores, maximizing its surface area and adsorption capacity. AC is a common supplement in tissue culture for many plant species as it has been observed to improve cell growth and development and enhance micropropagation, somatic embryogenesis, protoplast culture, anther and microspore culture, seed germination and root formation $[31,32]$. The mechanism of this beneficial effect is still unclear, but it has been hypothesized to be a combination of adsorbing inhibitory substances released during tissue culture [27, 33-35], decreasing accumulation of phenolic exudates [36, 37], improving medium $\mathrm{pH}$ [38], providing a dark environment which mimics soil conditions [39], and progressively releasing beneficial substances naturally present in the AC particles [40, 41].

Some improvements in shoot regeneration efficiency of 'RSL NFR' were also observed on media M3, M6 and M7, which are consistent with rates of up to $72 \%$ previously reported for other cultivars on medium M3 [14], with reports of zeatin being the most potent cytokinin, and with some reports that low amounts of BA induce a decrease in callus production and an increase in direct shoot induction [14, 22], respectively. Nevertheless, these studies make little mention to the overall quality of the shoots induced and whether an etiolated or abnormal morphology is present. It must be taken into account that shoot weakness can decrease plantlet survival and subsequent seed production.

\section{Conclusions}

Overall and out of all combinations tested, AC-enriched medium M19 produced the highest number of strong and healthy shoots as well as the most consistent results on recalcitrant cultivar 'RSL NFR'. M19 or small variations thereof might therefore pose a valuable alternative for fast and efficient multiple shoot production in lettuce cultivars which do not respond well to common media, potentially opening new opportunities for the biotechnological improvement of lettuce. This is also the first report of the use and beneficial effects of activated charcoal in lettuce tissue culture.

\section{Additional file}

Additional file 1. A spreadsheet containing all raw data generated and analyzed during this study. The first sheet contains the data for cultivar 'RSL NFR' and the second sheet contains the data for cultivar 'Winter Density'.

\section{Abbreviations}

AC: activated charcoal; BA: benzylaminopurine; IBA: indolebutyric acid; MS: Murashige and Skoog basal salt mixture; NAA: naphthaleneacetic acid; PAR: photosynthetically active radiation; SD: standard deviation; SH: Schenk and Hildebrandt basal salt mixture; TDZ: thidiazuron.

\section{Authors' contributions}

IA designed and conducted the experiments, analyzed the data, and wrote the manuscript. NP provided guidance for the experimental design and collaborated in the collection of results. IR provided guidance for the experimental design, general guidance, and editorial oversight. All authors read and approved the final manuscript.

\section{Acknowledgements}

The authors thank all laboratory members and the reviewers for their useful insight and suggestions.

\section{Competing interests}

IR and NP are inventors on a 'RSL NFR' patent application.

\section{Availability of data and materials}

The datasets supporting the conclusions of this article are included within the article and its additional file.

\section{Funding}

This work was supported by award 2P50-AT-002776 from the National Center for Complementary and Integrative Health $(\mathrm{NCClH})$ and from Rutgers University. Additionally, IA was partially supported by a fellowship from the USA-Spain Fulbright Commission and a research assistantship from Rutgers University. None of the funding bodies had any influence on the design of the study, the collection, analysis and interpretation of data, or the writing of the manuscript.

\section{Publisher's Note}

Springer Nature remains neutral with regard to jurisdictional claims in published maps and institutional affiliations.

Received: 23 January 2017 Accepted: 12 July 2017

Published online: 21 July 2017

References

1. FAOSTAT. Lettuce and chicory crop production. Food and Agriculture Organization Statistical Division. http://faostat3.fao.org/faostat-gateway/ go/to/search/lettuce/E. Accessed 10 July 2015.

2. Mohapatra U, McCabe MS, Power JB, Schepers F, Van Der Arend A, Davey MR. Expression of the bar gene confers herbicide resistance in transgenic lettuce. Transgenic Res. 1999;8:33-44.

3. Pang SZ, Ja FJ, Carney K, Stout J, Tricoli DM, Quemada HD, et al. Posttranscriptional transgene silencing and consequent tospovirus resistance in transgenic lettuce are affected by transgene dosage and plant development. Plant J. 1996;9:899-909. 
4. Pileggi M, Pereira AAM, Suva JDS, Pileggi SAV, Verma DPS. An improved method for transformation of lettuce by Agrobacterium tumefaciens with a gene that confers freezing resistance. Braz Arch Biol Technol. 2001:44:191-6.

5. Vanjildorj E, Bae TW, Riu KZ, Kim SY, Lee HY. Overexpression of Arabidopsis ABF3 gene enhances tolerance to drought and cold in transgenic lettuce (Lactuca sativa). Plant Cell Tissue Organ Cult. 2005;83:41-50.

6. Ichikawa Y, Tamoi M, Sakuyama H, Maruta T, Ashida H, Yokota A, et al. Generation of transplastomic lettuce with enhanced growth and high yield. GM Crops. 2010;1:322-6.

7. Ruhlman T, Ahangari R, Devine A, Samsam M, Daniell $H$. Expression of cholera toxin B-proinsulin fusion protein in lettuce and tobacco chloroplasts —oral administration protects against development of insulitis in non-obese diabetic mice. Plant Biotechnol J. 2007:5:495-510.

8. Boyhan D, Daniell H. Low-cost production of proinsulin in tobacco and lettuce chloroplasts for injectable or oral delivery of functional insulin and C-peptide. Plant Biotechnol J. 2011;9:585-98.

9. Park S, Elless MP, Park J, Jenkins A, Lim W, Chambers E IV, et al. Sensory analysis of calcium-biofortified lettuce. Plant Biotechnol J. 2009;7:106-17.

10. Cheng DM, Pogrebnyak N, Kuhn P, Krueger CG, Johnson WD, Raskin I. Development and phytochemical characterization of high polyphenol red lettuce with anti-diabetic properties. PLoS ONE. 2014;9:1-10.

11. Cheng DM, Pogrebnyak N, Kuhn P, Poulev A, Waterman C, Rojas-Silva P, et al. Polyphenol-rich Rutgers Scarlet Lettuce improves glucose metabolism and liver lipid accumulation in diet-induced obese C57BL/6 mice. Nutrition. 2014;30(Suppl 7-8):S52-8.

12. Ampomah-Dwamena C, Conner AJ, Fautrier AG. Genotypic response of lettuce cotyledons to regeneration in vitro. Sci Hortic (Amsterdam). 1997;71:137-45.

13. Xinrun Z, Conner AJ. Genotypic effects on tissue culture response of lettuce cotyledons. J Genet Breed. 1992;46:287-90.

14. Mohebodini M, Javaran MJ, Mahboudi F, Alizadeh H. Effects of genotype, explant age and growth regulators on callus induction and direct shoot regeneration of lettuce (Lactuca sativa L.). Aust. J Crop Sci. 2011;5:92-5.

15. Molnár Z, Virág E, Ördög V. Natural substances in tissue culture media of higher plants. Acta Biol Szeged. 2011;55:123-7.

16. Curtis IS, Power JB, Blackhall NW, De Laat AMM, Davey MR. Genotypeindependent transformation of lettuce using Agrobacterium tumefaciens. J Exp Bot. 1994:45:1441-9.

17. Koevary K, Rappaport L, Morris L. Tissue culture propagation of head lettuce. Hortic Sci. 1978;13:39-41.

18. Webb DT, Torres LD, Fobert P. Interactions of growth regulators, explant age, and culture environment controlling organogenesis from lettuce cotyledons in vitro. Can J Bot. 1984;62:586-90.

19. Doerschug $M$, Miller C. Chemical control of adventitious organ formation in Lactuca sativa explants. Am J Bot. 1967;54:410-3.

20. Teng WL, Liu YJ, Soong TS. Rapid regeneration of lettuce from suspension culture. Hortic Sci. 1992;27:1030-2.

21. Hunter DC, Burritt DJ. Improved adventitious shoot production from cotyledon explants of lettuce (Lactuca sativa L.). Sci Hortic (Amsterdam). 2002;95:269-76

22. Latif $B$, Javaran MJ, Alizadeh H, Memari HR, Mohammadi R. Interactions of genotype and plant growth regulators affecting direct shoot regeneration of lettuce (Lactuca sativa L.). Int J Biosci. 2014;5:315-22.

23. Kanamoto $\mathrm{H}$, Yamashita A, Asao H, Okumura S, Takase H, Hattori M, et al. Efficient and stable transformation of Lactuca sativa L. Cv. Cisco (lettuce) plastids. Transgenic Res. 2006;15:205-17.
24. Lichter R. Induction of haploid plants from isolated pollen of Brassica napus. Zeitschrift für Pflanzenphysiologie. 1982;105:427-34.

25. Anu A, Babu K, Peter K. Variations among somaclones and its seedling progeny in Capsicum annuum. Plant Cell Tissue Organ Cult. 2004;76:261-7.

26. Zdravković-Korać S, Muhovski Y, Druart P, Ćalić D, Radojević L. Agrobacterium rhizogenes-mediated DNA transfer to Aesculus hippocastanum $L$. and the regeneration of transformed plants. Plant Cell Rep. 2004;22:698-704.

27. Fridborg G, Pedersén M, Landström LE, Eriksson T. The effect of activated charcoal on tissue cultures: adsorption of metabolites inhibiting morphogenesis. Physiol Plant. 1978;43:104-6.

28. Nissen SJ, Sutter EG. Stability of IAA and IBA in nutrient medium to several tissue culture procedures. HortScience. 1990;25:800-2.

29. Ebert A, Taylor F, Blake J. Changes of 6-benzylaminopurine and 2,4-dichlorophenoxyacetic acid concentrations in plant tissue culture media in the presence of activated charcoal. Plant Cell Tissue Organ Cult. 1993;33:157-62.

30. Druart P, De Wuif O. Activated charcoal catalyses sucrose hydrolysis during autoclaving. Plant Cell Tissue Organ Cult. 1993;32:97-9.

31. Pan MJ, Van Staden J. The use of charcoal in in vitro culture-a review. Plant Growth Regul. 1998;26:155-63.

32. Thomas TD. The role of activated charcoal in plant tissue culture. Biotechnol Adv. 2008;26:618-31.

33. Horner M, McComb J, Street H. Ethylene production and plantlet formation by Nicotiana anthers cultured in the presence and absence of charcoal. J Exp Bot. 1977;28:1365-72.

34. Weatherhead MA, Burdon J, Henshaw GG. Some effects of activated charcoal as an additive to plant tissue culture media. Zeitschrift für Pflanzenphysiologie. 1978;89:141-7.

35. Weatherhead MA, Burdon J, Henshaw GG. Effects of activated charcoal as an additive to plant tissue culture media: part 2. Zeitschrift für Pflanzenphysiologie. 1979;94:399-405.

36. Carlberg I, Glimelius K, Eriksson T. Improved culture ability of potato protoplasts by use of activated charcoal. Plant Cell Rep. 1983;2:223-5.

37. Teixeria J, Sondahl M, Kirby E. Somatic embryogenesis from immature inflorescences of oil palm. Plant Cell Rep. 1994;13:247-50.

38. Owen HR, Wengerd D, Miller AR. Culture medium $\mathrm{pH}$ is influenced by basal medium, carbohydrate source, gelling agent, activated charcoal, and medium storage method. Plant Cell Rep. 1991;10:583-6.

39. Dumas E, Monteuuis O. In vitro rooting of micropropagated shoots from juvenile and mature Pinus pinaster explants: influence of activated charcoal. Plant Cell Tissue Organ Cult. 1995;40:231-5.

40. Johansson L, Eriksson T. Induced embryo formation in anther culture of several Anemone species. Physiol Plant. 1977;40:172-4.

41. Johansson L, Calleberg E, Gedin A. Correlations between activated charcoal, Fe-EDTA and other organic media ingredients in cultured anthers of Anemone canadensis. Physiol Plant. 1990;80:243-9.

\section{Submit your next manuscript to BioMed Central and we will help you at every step:}

- We accept pre-submission inquiries

- Our selector tool helps you to find the most relevant journal

- We provide round the clock customer support

- Convenient online submission

- Thorough peer review

- Inclusion in PubMed and all major indexing services

- Maximum visibility for your research

Submit your manuscript at www.biomedcentral.com/submit
C BioMed Central 